Tustiyani, I. • D. R. Nurjanah · S. S. Maesyaroh · J. Mutakin

\title{
Identifikasi keanekaragaman dan dominansi gulma pada lahan pertanaman jeruk (Citrus Sp.)
}

\section{Identification of diversity and dominance of weeds on citrus fruit (Citrus Sp.) crop land}

Diterima : 9 Oktober 2018/Disetujui : 20 Maret 2019 / Dipublikasikan : 31 Maret 2019

CDepartment of Crop Science, Padjadjaran University

\begin{abstract}
Weeds was plants that interfere with cultivated plants. The aim of this research was to identify the diversity and dominance of weeds on Citrus (Citrus sp.) in medium land of Garut. The study was conducted in April to June 2018. The qualitative method is used through case study. Sampling was conducted on 5 differents plot weed with size $50 \mathrm{~cm} \times 50 \mathrm{~cm}$ per plot. Each plot had 5 sampling points. Weed samples were collected and it was identified per species according to the weed group, then it was calculated by Summed Dominance Ratio to see weed dominancy at each site locations. The results of the study identified 6 types of weed grass, 3 weed cyperus types and 13 types of broad-leaf weeds with low diversity index. The dominant types of weeds in citrus was Cyperus rotundus and Amaranthus spinosus L.
\end{abstract}

Keywords: Ccitrus • Diversity · Dominant . Identification $\cdot$ Weed.

Sari Gulma merupakan tumbuhan yang mengganggu tanaman budidaya. Penelitian bertujuan untuk mengidentifikasi keanekaragaman dan dominansi gulma pada lahan pertanaman jeruk (Citrus sp.) di dataran medium Kabupaten Garut. Penelitian dilaksanakan pada Bulan April sampai Juni 2018. Metode penelitian adalah statistik kualitatif melalui studi kasus. Pengambilan sampel dilakukan pada 5 plot yang berbeda dengan luas pengambilan sempel gulma masing-masing $50 \mathrm{~cm} \times 50 \mathrm{~cm} /$ plot.

\footnotetext{
Dikomunikasikan oleh Muhammad Irianto

Tustiyani, I. ${ }^{1}$ · D. R. Nurjanah ${ }^{2}$. S. S. Maesyaroh ${ }^{1}$.

J. Mutakin ${ }^{1}$

${ }^{1}$ Dosen Program Studi Agroteknologi, Fakultas Pertanian,

Universitas Garut

2 Alumni Program Studi Agroteknologi, Fakultas

Pertanian, Universitas Garut

korespondensi: isnatustiyani@gmail.com;
}

Setiap lahan terdapat 5 titik pengambilan sampel. Setelah didapatkan sampel gulma, maka dilakukan identifikasi gulma dan Summed Dominance Ratio. Hasil penelitian teridentifikasi 6 jenis gulma rumput, 3 gulma teki dan 13 jenis gulma daun lebar dengan indeks keanekaragaman yang rendah. Jenis gulma yang dominan adalah gulma Ciperus rotundus dan Amaranthus spinosus $\mathrm{L}$.

Kata kunci: Dominansi - Gulma • Identifikasi . Jeruk · Keanekaragaman.

\section{Pendahuluan}

Gulma merupakan tumbuhan yang mengganggu pertumbuhan tanaman budidaya atau merugikan kepentingan manusia sehingga manusia berusaha untuk mengendalikannya (Sembodo, 2010; Kilkoda, 2015). Jenis gulma meliputi gulma rumput (grasses), gulma golongan tekian (seedges) dan gulma golongan berdaun lebar (broad leaves). Gulma merupakan salah satu faktor yang menghambat pertumbuhan tanaman selain faktor alam, genetik dan budidaya tanaman (Kilkoda et. al., 2015). Gangguan gulma dapat menyebabkan tanaman kerdil, daun-daun menguning dan produksi rendah (Najiyati dan Danarti, 2003; Solahudin, $d k k$, 2010; Palijama, $d k k$, 2012; Sari dan Rahayu, 2013; Purnamasari, $d k k$, 2017; Tampubolon, $d k k$, 2018).

Beberapa kerugian yang disebabkan serangan gulma antara lain: menghambat pertumbuhan dan menurunnya hasil tanaman akibat persaingan dalam mendapatkan unsur hara, air, cahaya dan ruang tumbuh; menurunkan kualitas hasil tanaman; sebagai tanaman inang bagi hama dan penyakit; dapat menimbulkan 
keracunan bagi tanaman pokok yang dikenal sebagai alelopati dan mempersulit pekerjaan di lapangan (Wibowo, 2006; Umiyati dan Kurniadie, 2016).

Keragaman gulma penting dipelajari untuk mengetahui komposisi dan struktur gulma pada lahan tanaman jeruk dan dapat menentukan pengendalian yang tepat. Keragaman gulma dipengaruhi oleh kondisi lingkungan (Perdana dan Syam, 2013). Banyak faktor yang mempengaruhi keragaman gulma pada tiap lokasi pengamatan, seperti cahaya, unsur hara, pengolahan tanah, cara budidaya tanaman, serta jarak tanam atau kerapatan tanaman yang digunakan berbeda serta umur tanaman jeruk tersebut. Spesies gulma juga dipengaruhi oleh kerapatan tanaman, kesuburan tanah, pola budidaya dan pengolahan tanah (Aldrich and Kremer, 1997). Sebaran gulma antara satu daerah dengan daerah lainnya berbeda sesuai dengan faktor yang mempengaruhinya. Identifikasi gulma serta pengenalan jenis-jenis gulma dominan merupakan langkah awal dalam menentukan keberhasilan pengendalian gulma. Penelitian ini bertujuan untuk mengetahui keragaman dan dominansi gulma di lahan pertanaman jeruk.

Metode. Studi kasus tahun 2018 dilaksanakan pada lahan pertanaman jeruk milik petani di wilayah dataran medium Kabupaten Garut, yaitu Kampung Cibolerang, Desa Karangsari, Kecamatan Karangpawitan (ketingguan tempat $715 \mathrm{~m}$ dpl dan tipe curah hujan sedang menurut Smith dan Ferguson), dengan jumlah lahan sebanyak 5 lahan. Percobaan ini dilaksanakan pada bulan April sampai Juni 2018.

Bahan dan alat yang digunakan adalah gulma pada lahan pertanaman jeruk dataran medium Kabupaten Garut, kuadran (Frame) ukuran $0,5 \times 0,5 \mathrm{~m})$, gunting, wadah, kantong plastik, kantong kertas, timbangan analitik, alat tulis, dan penggaris.

Metode yang di gunakan adalah statistik kualitatif melalui studi kasus pada gulma tanaman jeruk. Penelitian di buat lima blok dengan mengambil lima sampel, pada setiap lokasi sampel dilakukan analisa vegetasi gulma secara acak (5 kali) untuk tiap luasan lahan pertanaman jeruk dengan metode kuadran, ukuran kuadran yang digunakan 0,5 m x 0,5 m.

Pengambilan Sampel Gulma. Sampel gulma diambil sebanyak 5 kali pada setiap titik lokasi lahan petani terpilih. Pengambilan dilakukan secara manual dengan menggunakan tangan seperti proses penyiangan pada umumnya. Pengambilan sampel gulma pada setiap titik menggunakan bingkai atau frame, kemudian gulma dibersihkan dari lumpur atau kotoran yang menempel disekitar perakaran dan dimasukan kedalam amplop atau plastik secara terpisah, untuk selanjutnya dilakukan identifikasi. Pengambilan sampel gulma dilakukan setiap dua minggu sekali selama tiga bulan.

Identifikasi Gulma. Identifikasi gulma yang ditemukan dari masing-masing titik pengamatan dilakukan dengan cara melihat secara visual bentuk morfologi gulma tersebut, kemudian dicocokkan dengan pustaka (Caton, et.al., 2011) Langkah selanjutnya adalah mengelompokkan gulma berdasarkan spesies dan dihitung jumlahnya apabila sudah diketahui spesies gulma tersebut. Identifikasi dilakukan untuk memperoleh data keragaman dan dominasi jenis gulma pada lahan pertanaman jeruk. Nilai SDR dihitung dengan menggunakan rumus sebagai berikut :

$$
\begin{gathered}
\text { Summed Dominance Ratio } \\
(\mathrm{SDR})=\frac{\text { kerapatan relatif }+ \text { frekuensi relatif }}{2}
\end{gathered}
$$

\section{Hasil dan Pembahasan}

Identifikasi Gulma. Hasil pengamatan gulma pada lahan pertanaman jeruk di Kecamatan Karangpawitan Kabupaten Garut menunjukan bahwa jenis gulma yang teridentifikasi secara umum tercatat ada 22 jenis gulma. Tabel 1 menunjukkan bahwa spesies gulma yang termasuk ke dalam gulma rumput terdapat 6 spesies, yaitu: Cynodon dactylon, Digitaria ciliaris, Eleusine indica, Imperata cylindrica, Ischaemum rugosum, dan Rottboellia cochinchinensis. Tercatat 3 spesies gulma teki, yaitu: Cyperus rotundus, Cyperus killingia dan Fimbristylis miliacea, serta terdapat 13 spesies gulma berdaun lebar, yaitu: Ageratum conyzoides, Alternanthera sessilis, Amaranthus spinosus, Commelina diffusa, Ludwigia octovalvis, Mimosa pudica, Portulaca oleracea, Borreria laevis, Cleome rutidospermae, Capsicum frutescent, Phyllanthus niruri, Alternanthera sp., dan Brassica campestris (Caton et.al., 2011).

Jumlah jenis gulma terbanyak dari hasil identifikasi adalah jenis gulma berdaun lebar, yaitu sebanyak 13 jenis, dimungkinkan karena lahan yang cocok untuk pertumbuhan gulma jenis ini. Menurut Tjitrosoepomo, dkk. (1987), 
golongan gulma berdaun lebar menyukai tanah sedikit lembab, sedangkan gulma jenis teki dan rumput lebih menyukai lahan terbuka. Disekitar pertanaman jeruk merupakan lahan yang lembab karena ternaungi oleh tanaman jeruk berumur 5 tahun.

Tabel 1. Identifikasi Gulma pada Lahan Pertanaman Jeruk.

\begin{tabular}{lll}
\hline No & Gulma & Nama Lokal \\
\hline & Rumput & \\
1 & C. dactylon & Grintingan \\
2 & D. ciliaris & Cakar Ayanm \\
3 & E. indica & Belulangan \\
4 & I. cylindrical & Alang Alang \\
5 & I. rugosum & Blembem \\
6 & R. cochinchinensis & Branjangan \\
& Teki & \\
7 & C. rotundus & Teki Ladang \\
8 & C. killingia & Wudelan \\
9 & F. miliacea & Adas-adasan \\
& Daun Lebar & \\
10 & A. conyzoides & Babadotan \\
11 & A. sessilis & Kremah \\
12 & A. spinosus & Bayam Berduri \\
13 & C. diffusa & Brambangan \\
14 & L. octovalvis & Lakum Air \\
15 & M. pudica & Putri Malu \\
16 & P. oleracea & Gelang \\
17 & B. laevis & Rumput kancing \\
18 & C. rutidospermae & Mamam \\
19 & C. frutescent & Cabai rawit \\
20 & P. niruri & Meniran \\
21 & Alternanthera sp. & Kremah \\
22 & B. campestris & Mustard liar \\
\hline & &
\end{tabular}

Hasil data analisis SDR gulma pada lahan pertanaman jeruk di dataran medium Kabupaten Garut dapat dilihat pada Tabel 2. Gulma yang memiliki nilai SDR tertinggi pada lahan pertanaman jeruk 1 terdapat pada golongan gulma teki, yaitu: Cyperus rotundus sebesar $14.73 \%$. Cyperus rotundus merupakan jenis gulma yang bisa tumbuh diberbagai kondisi lingkungan. Cyperus rotundus merupakan jenis yang mendominasi daerah perkebunan gulma ini dan dapat tumbuh pada bermacam-macam keadaan tanah. Cyperus rotundus merupakan jenis gulma yang berbahaya (noxious).

Gulma yang memiliki nilai SDR tertinggi pada areal pertanaman jeruk 2 terdapat pada golongan gulma daun lebar, yaitu : Amaranthus spinosus L. sebesar $14.72 \%$. Amaranthus spinosus L. memiliki siklus hidup tahunan, dapat berkembang biak dengan biji, gulma ini dapat tumbuh hingga ketinggian $1800 \mathrm{~m} \mathrm{dpl}$, serta membutuhkan banyak cahaya matahari. Gulma daun lebar dapat berkembangbiak melalui biji dan mempunyai kemampuan beradaptasi dengan lingkungan serta berbunga sepanjang tahun.

Gulma yang memiliki nilai SDR tertinggi pada areal pertanaman jeruk 3 dan 4 terdapat pada golongan gulma teki, yaitu : Cyperus rotundus sebesar $34.70 \%$ dan $22.46 \%$. Keadaan tanaman jeruk yang sudah besar dan lebar sehingga membuat lahan 3 dan 4 melakukan penyiangan dengan cara manual yaitu dengan mencabuti gulma secara langsung. Cara seperti ini kurang efektif karena tunas gulma yang masih kecil seringkali terlewat.

Tabel 2. Nilai SDR (Summed Dominance Ratio ) Gulma pada Lahan Pertanaman Jeruk.

\begin{tabular}{|c|c|c|c|c|c|}
\hline \multirow{2}{*}{ Gulma } & \multicolumn{5}{|c|}{ Summed Dominance Ratio (SDR) } \\
\hline & L1 & L2 & L3 & L4 & L5 \\
\hline C. dactylon & 5.09 & 8.01 & & & 2.55 \\
\hline D. ciliaris & 2.93 & & 3.20 & & \\
\hline E. indica & 8.19 & 9.29 & 4.82 & 8.19 & 6.78 \\
\hline I. cylindrica & & & 5.08 & & \\
\hline I. rugosum & 3.40 & 2.51 & 2.89 & 1.42 & \\
\hline $\begin{array}{l}R . \\
\text { cochinchinensis }\end{array}$ & 5.96 & 6.42 & 2.98 & 1.34 & 1.53 \\
\hline C. rotundus & $14.73^{*}$ & 14.19 & $34.70^{*}$ & $22.46^{*}$ & 9.40 \\
\hline C. killingia & 2.27 & 1.33 & & & 1.53 \\
\hline F. miliacea & 1.06 & & & & 1.53 \\
\hline A. Conyzoides & 8.90 & 3.46 & 10.73 & 5.78 & 1.53 \\
\hline A. sessilis & 2.11 & 7.35 & 2.72 & 1.42 & 3.50 \\
\hline A. spinosus L. & 13.47 & $14.72^{*}$ & & 11.16 & $28.02^{*}$ \\
\hline C. diffusa & 2.11 & 5.09 & & & \\
\hline L. octovalvis & 0.90 & & & & \\
\hline M. pudica & & & & & 1.53 \\
\hline P. oleracea & 3.01 & 5.52 & & 7.24 & 13.63 \\
\hline B. laevis & 2.70 & 2.86 & 2.72 & 4.18 & 9.19 \\
\hline C. & 2.03 & 1.78 & 5.17 & & \\
\hline rutidospermae & & & & & \\
\hline C. frutescent & 0.98 & 1.71 & & 1.34 & \\
\hline P. niruri & 0.90 & & 4.43 & 1.34 & 1.53 \\
\hline $\begin{array}{l}\text { Alternanthera } \\
\text { sp. }\end{array}$ & 5.25 & 7.20 & 3.20 & 14.61 & 3.65 \\
\hline B. campestris & 14.02 & 8.56 & 17.36 & 19.53 & 14.07 \\
\hline Total & $100 \%$ & $100 \%$ & $100 \%$ & $100 \%$ & $100 \%$ \\
\hline
\end{tabular}

Keterangan : * : menunjukan nilai SDR tertinggi L : lahan

Ukuran tanaman jeruk relatif besar pada lahan ke-3 dan 4, sehingga tanaman menaungi gulma. Keadaan lingkungan seperti ini cocok untuk pertumbuhan gulma golongan teki. 
Rumput teki banyak tumbuh di tempat terbuka atau tidak terkena sinar matahari secara langsung seperti tumbuh di lahan pertanian yang tidak terlalu kering, ladang, kebun, tegalan, pinggir jalan, yang hidup sebagai gulma karena sangat susah untuk diberantas (Gunawan, 1998).

Perbedaan jenis gulma disebabkan oleh terjadinya perbedaan pengelolaan tanaman, antara lain pengaturan air dan pemupukan serta adanya perbedaan morfologi dan karakter tanaman penyusun yang dapat merubah mikroklimat sehingga menimbulkan respons yang berbeda pada jenis gulma (Mercado, 1979).

Gulma yang memiliki nilai SDR tertinggi pada areal pertanaman jeruk ke-5 terdapat pada golongan gulma daun lebar, yaitu : Amaranthus spinosus L. sebesar $28.02 \%$. Hal ini terjadi karena golongan gulma daun lebar sangat beragam sehingga hampir mendominasi di lahan penelitian ke-5. Golongan ini memiliki anggota dengan jumlah yang paling banyak dan paling beragam. Semua jenis gulma yang tidak termasuk dalam famili Poaceae (rumput) dan Cyperaceae (teki) adalah golongan daun lebar (Sembodo, 2010).

\section{Kesimpulan}

1. Hasil penelitian teridentifikasi 6 jenis gulma rumput, 3 gulma teki dan 13 jenis gulma daun lebar dengan indeks keanekaragaman yang rendah.

2. Gulma yang dominan pada lahan pertanaman jeruk dataran medium adalah Cyperus rotundus dan gulma Amaranthus spinosus.

\section{Ucapan Terima Kasih}

Penulis mengucapkan terima kasih kepada Kementrian Riset, Teknologi dan Perguruan Tinggi atas pemberian dana penelitian pada skim Penelitian Dosen Pemula (PDP) tahun angaran 2018. Terima kasih juga kami ucapkan kepada Petani Jeruk di Kampung Cibolerang, Desa Karangsari Kecamatan Karangpawitan, Kabupaten Garut (Pak Amin, Pak Atik, dan Pak Fahmi), seluruh Civitas Akademika Fakultas Pertanian Universitas Garut, dan semua pihak yang telah membantu terselenggaranya kegiatan penelitian ini.

\section{Daftar Pustaka}

Aldrich, R.J., dan R.J. Kremer 1997. Principles in Weed Management. Second Edition. Ames Iowa. Iowa State University Press.

Caton, B.P, M. Mortimer, J.E. Hill, and D.E. Johnson. 2011. Panduan Lapang Praktis Gulma Padi Asia. International Rice Research Institute. Makati City, Philippine.

Gunawan, D. 1998. Tumbuhan Obat Indonesia. Yogyakarta. Pusat Penelitian Obat Tradisional UGM.

Kilkoda, A.K. 2015. Respon Allelopati Gulma Ageratum Conyzoides Dan Borreria Alata Terhadap Pertumbuhan Dan Hasil Tiga Varietas Kedelai (Glycine Max). Jurnal Agro, 2 (1) : 39-49.

Kilkoda, A.K., T. Nurmala, dan D. Widayat. 2015. Pengaruh keberadaan gulma (Ageratum conyzoides dan Boreria alata) terhadap pertumbuhan dan hasil tiga ukuran varietas kedelai (Glycine max L. Merr) pada percobaan pot bertingkat. Jurnal Kultivasi, Vol. 14(2) : 1-9

Mercado, B.L. 1979. Introduction to Weed Science. Southeast Asian Regional Center for Graduate Study and Research in Agriculture (SEARCA), Leguna, Philippines.

Najiyati. S dan Danarti, 2003. Budidaya dan Penanganan Pascapanen. Edisi revisi. Yogyakarta. Kanisius.

Palijama, W., J. Riry dan A.Y. Wattimena. 2012. Komunitas Gulma Pada Pertanaman Pala (Myristica Fragrans H) Belum Menghasilkan Dan Menghasilkan Di Desa Hutumuri Kota Ambon. Agrologia, 1 (2): 134-142.

Perdana, E.O., Chairul, dan Z. Syam. 2013. Analisis Vegetasi Gulma Pada Tanaman Buah Naga Merah (Hylocereus polyrhizus, L.) Di Kecamatan Batang Anai, Kabupaten Padang Pariaman, Sumatera Barat. Jurnal Biologi Universitas Andalas 2(4): 242-248.

Purnamasari, C.D., Tyasmoro, S.Y., Sumarni, T. 2017. Pengaruh Teknik Pengendalian Gulma Pada Tanaman Padi (Oryza Sativa L). Jurnal Produksi Tanaman 5 (5): 870879.

Sari, H. F. M., dan S.S. B. Rahayu. 2013. JenisJenis Gulma Yang Ditemukan Di Perkebunan Karet (Hevea Brasiliensis Roxb.) Desa Rimbo Datar Kabupaten 50 Kota Sumatera Barat. Biogenesis, (1):28-32. 
Solahudin, M., K. B. Seminar, I.W. Astika, dan A. Buono. 2010. Pendeteksian Kerapatan Dan Jenis Gulma Dengan Metode Bayes Dan Analisis Dimensi Fraktal Untuk Pengendalian Gulma Secara Selektif. Jurnal Keteknikan Pertanian, 24 (2) : 129-135.

Sembodo, D. R. J. 2010. Gulma dan Pengelolaannya. Graha Ilmu. Yogyakarta

Tampubolon, K., F.N. Sihombing, Z. Purba, S.T.S. Samosir, dan S. Karim. 2018. Potensi Metabolit Sekunder Gulma Sebagai Pestisida Nabati Di Indonesia. Jurnal Kultivasi, 17 (3): 683-693.
Tjitrosoepomo, G., M. Soerjani, dan Kostermans. 1987. Weeds of rice in Indonesia. Balai Pustaka. Jakarta.

Umiyati, D. dan Kurniadie, D. 2016. Pergesaran populasi gulma pada olah tanah dan pengendalian gulma yang berbeda pada tanaman kedelai. Jurnal Kultivasi, Vol. 15(3): 150-153.

Wibowo, A. (2006). Gulma di Hutan Tanaman dan Upaya Pengendaliannya. Pusat Penelitian dan Pengembangan Hutan Tanaman. Badan Penelitian dan Pengembangan Kehutanan. Bogor. 